\title{
The Adsorption of Nitromethane on the Au (111) Surface
}

\author{
J. R. B. Gomes and F. Illas* \\ Departament de Química Física i Centre de Recerca en Química Teòrica, Universitat de Barcelona, \\ C/ Martí i Franquès 1, E-08028 Barcelona, Spain \\ Tel.: +34 93402 1229, Fax: +34 93402 1231, E-mail: f.illas@qf.ub.es \\ URL: http://www.qf.ub.es/c1/xino.html \\ * Author to whom correspondence should be addressed.
}

Received: 26 September 2001 / Accepted: 19 October 2001 / Published: 13 November 2001

\begin{abstract}
The density functional theory (DFT) based hybrid-method B3LYP has been used to study the interaction of the nitromethane molecule $\left(\mathrm{CH}_{3} \mathrm{NO}_{2}\right)$ with the $\mathrm{Au}(111)$ surface. The perfect $\mathrm{Au}(111)$ surface has been represented by a rather large cluster model, $\mathrm{Au}_{22}$, that was in turn used to extract information about the preferred adsorption geometry of the $\mathrm{CH}_{3} \mathrm{NO}_{2}$ species. In order to extract energetic information about the stability of adsorbed nitromethane, calculations were also performed for the gas-phase $\mathrm{CH}_{3} \mathrm{NO}_{2}$ molecule. The results obtained here are used to interpret experimental data. The computed geometry for adsorbed $\mathrm{CH}_{3} \mathrm{NO}_{2}$ agrees with the structure proposed from a previous experimental work.
\end{abstract}

Keywords: Nitromethane, density functional theory, $\mathrm{Au}(111)$, chemisorption, molecular geometry.

\section{Introduction}

The knowledge of the chemical behavior of nitrogen containing compounds is of considerable interest in many industrial applications [1,2]. Nitromethane is a very interesting molecule in adsorption phenomena due to its structural simplicity and ease of handling. Also, the reactions involving nitromethane are important since it is the archetype of a class of simple high explosives and monopropellants in rocket thrusters $[3,4]$. Fundamental studies of the adsorption properties of nitromethane on transition metal surfaces are needed to characterize and understand the selective activation of $\mathrm{C}-\mathrm{H}$, 
C-N or N-O bonds. Also, they may be used to extract information about reaction pathways and products that may be formed. Previous studies on the homogenous catalysis of nitromethane show that it forms in one stage the $\mathrm{CH}_{3} \mathrm{ONO}$ isomer [5,6]. Adsorbed methyl nitrite was found previously to be capable of producing surface methoxy species [7] which are known to be important intermediates in the methanol oxidation catalyzed by metal surfaces [8-11].

Only but a few studies concerning the adsorption of nitromethane on transition metal surfaces can be found in the literature [12-17]. Namely, there are several studies concerning the interaction of the simplest nitroalkane with the $\mathrm{Ni}(111)$ [12], $\mathrm{Rh}(111)$ [13], $\mathrm{Pt}(111)$ [14,15] and $\mathrm{Au}(111)$ [16] singlemetal surfaces and also with the Pt-Sn alloy [17]. From these experimental studies it is concluded that nitromethane is weakly adsorbed and that it desorbs in large quantities upon heating. Only a small portion of adsorbed nitromethane suffers decomposition. The products obtained depend strongly on the metal support used and this is caused by the different way on how the $\mathrm{C}-\mathrm{N}$ and $\mathrm{N}-\mathrm{O}$ bonds are activated. On the platinum surface, the major decomposition path of adsorbed nitromethane is the dissociation of $\mathrm{C}-\mathrm{H}$ and $\mathrm{N}-\mathrm{O}$ bonds which forms $\mathrm{H}_{2}, \mathrm{H}_{2} \mathrm{O}, \mathrm{CO}$ and $\mathrm{NO}$ and leaves $\mathrm{CN}$ on the surface that desorbs as $\mathrm{C}_{2} \mathrm{~N}_{2}$ [14]. Thus, $\mathrm{C}-\mathrm{N}$ bond scission does not take place on the $\operatorname{Pt}(111)$ surface. The same appears to be true for the nickel (111) surface [12], i. e., the decomposition of nitromethane, studied by means of temperature-programmed desorption (TPD) and Fourier transform-reflection-absorption infrared spectroscopy (FT-RAIRS), produce as major products $\mathrm{HCN}, \mathrm{H}_{2}$ and adsorbed oxygen. This behavior contrasts with that of nitromethane on the $\mathrm{Rh}(111)$ surface upon heating. Hwang et al. [13] using TPD and Auger electron spectroscopy (AES) observed for the surface of rhodium $\mathrm{CO}, \mathrm{N}_{2}, \mathrm{H}_{2}$ and $\mathrm{CO}_{2}$ as major products, smaller amounts of $\mathrm{CH}_{4}$ and trace quantities of $\mathrm{HCN}, \mathrm{NO}$ and $\mathrm{H}_{2} \mathrm{O}$. Therefore, the major decomposition path is governed by the complete dissociation of the $\mathrm{C}-\mathrm{N}$ and $\mathrm{N}-\mathrm{O}$ bonds leaving on the surface $\mathrm{N}$ and $\mathrm{O}$ atoms combined with surface $\mathrm{CH}_{\mathrm{x}}$ species. On the gold surface the TPD spectra shows one single peak due to desorption of $\mathrm{CH}_{3} \mathrm{NO}_{2}$ and no other peaks associated with the other smaller molecules referred above were observed [16]. Nitromethane is proposed to adsorb on these metal surfaces in a monodentate geometry, with only one oxygen atom approaching the surface and the $\mathrm{C}-\mathrm{N}$ axis tilted away from the normal to the surface and the adsorption energy is predicted to be close to $10 \mathrm{kcal} / \mathrm{mol}[15,16]$.

\section{Computational details}

In the present work, the cluster model approach combined with the density functional theory (DFT) based B3LYP method have been used to investigate the adsorption geometry of nitromethane adsorbed on the Au (111) surface. The B3LYP hybrid method is known to provide very good results for systems where transition metal atoms are present [18-25]. It uses an exchange functional that mixes the nonlocal Fock exchange with the gradient corrected form proposed by Becke [26] and adds the functional correlation proposed by Lee et al. [27] based in the previous work of Colle and Salvetti [28,29]. To model the metal surface, the same $\mathrm{Au}_{22}$ cluster model used in a previous work to study the adsorption of the methyl nitrite molecule on the $\mathrm{Au}(111)$ surface [24] has been used and it is depicted in Figure 1. This reasonably large cluster with $\mathrm{C}_{\mathrm{s}}$ symmetry is made up of two metal layers. The first metal layer contains fourteen gold atoms and the second layer contains eight metal atoms. No additional layers were considered because of the local nature of the chemisorption phenomena. In order to make the calculations feasible the gold atoms in the cluster model were assigned to different regions that are treated 
differently in terms of the basis set employed. The Au atoms closest to the adsorption site, four from the first layer and three from the second layer, define the inner region, blue atoms in Figure 1. The atoms in this region were treated with the LANL2DZ basis set derived by Hay and Wadt [30]. This basis set explicitly consider the outer $5 \mathrm{~s}^{2} 5 \mathrm{p}^{6} 5 \mathrm{~d}^{10} 6 \mathrm{~s}^{1}$ electrons in gold atoms by a double-zeta basis set while the inner core electrons were replaced by the relativistic effective core potential, RECP, of Hay and Wadt [30]. The gold atoms farther from the adsorption site, outer region, were described by the LANL2MB [30] basis set which differs from the LANL2DZ basis set by the use of a minimal basis instead of the double-zeta one to treat the valence electrons. These two different regions are also illustrated in Figure 1. The standard split valence basis set, 6-31G, plus polarization and diffuse functions, resulting in a $6-31+\mathrm{G}^{*}$ basis, has been employed to describe the non-metallic atoms. All calculations were carried out by means of the Gaussian 98 suite of programs [31].

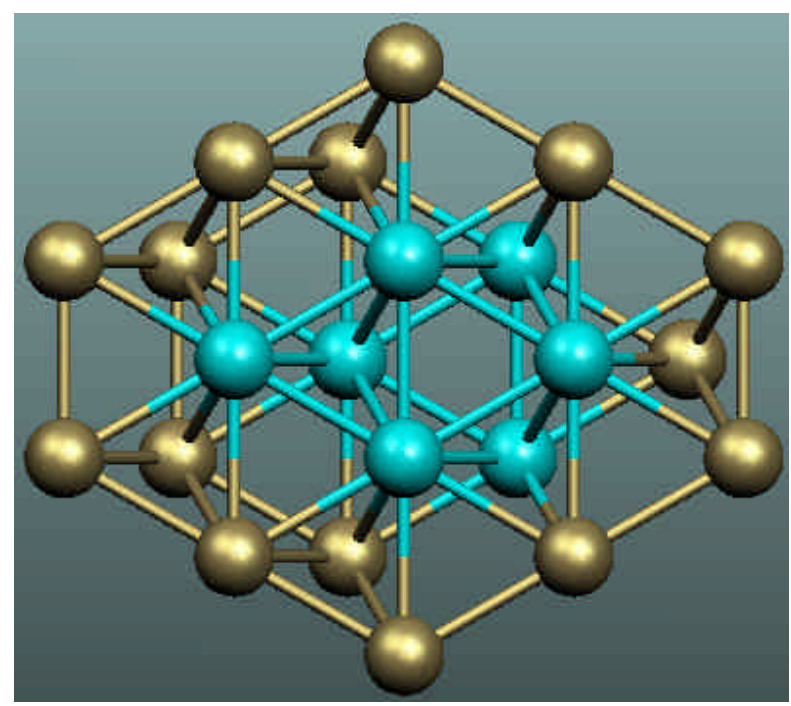

Figure 1. Top view of the $\mathrm{Au}_{22}(14,8)$ cluster used to model the (111) gold surface.

\section{Results}

In the set of calculations here reported, the adsorption energy of the nitromethane molecule was computed as

$$
\mathbf{E}_{\mathbf{a d s}}=\mathbf{E}\left(\mathrm{CH}_{3} \mathrm{NO}_{2} / \mathrm{Au}_{22}\right)-\mathbf{E}\left(\mathrm{CH}_{3} \mathrm{NO}_{2}\right)-\mathbf{E}\left(\mathrm{Au}_{22}\right)
$$

The first term in equation 1 is the total energy of the $\mathrm{CH}_{3} \mathrm{NO}_{2}+\mathrm{Au}_{22}$ supermolecule and the second and third terms refer to the total energy of the separated fragments. Thus, to obtain $\mathbf{E}_{\mathbf{a d s}}$ it is needed to calculate all these quantities separately.

Let us start with the nitromethane molecule in the gas-phase. The computed geometric and energetic parameters for the isolated $\mathrm{CH}_{3} \mathrm{NO}_{2}$ molecule are collected in Table 1. The atomic labels are shown in Figure 2. The basis set chosen combined with the B3LYP method were proven to be sufficient enough to yield geometries in good agreement both with experimental data and with values computed with the, in principle, more accurate $\operatorname{CCSD}(\mathrm{T})$ method [24]. 


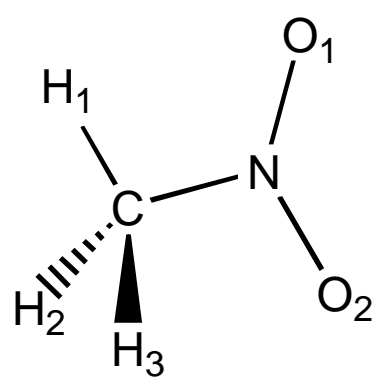

Figure 2. Atomic labeling used to distinguish the atoms in the nitromethane molecule.

Table 1. Geometric parameters and total energy for the nitromethane molecule calculated using the B3LYP method and the $6-31+\mathrm{G}^{*}$ basis set.

\begin{tabular}{|c|c|c|c|c|c|}
\hline Parameter & eclipsed & staggered & exp. [32] & eclipsed [33] $^{\mathrm{a}}$ & staggered [33] $^{\mathrm{a}}$ \\
\hline $\mathrm{d}\left(\mathrm{C}-\mathrm{H}_{1}\right)(\AA)$ & 1.088 & 1.093 & $1.089 \pm 0.005$ & 1.077 & 1.081 \\
\hline $\mathrm{d}\left(\mathrm{C}-\mathrm{H}_{2,3}\right)(\AA)$ & 1.091 & 1.089 & $1.089 \pm 0.005$ & 1.080 & 1.077 \\
\hline $\mathrm{d}(\mathrm{C}-\mathrm{N})(\AA)$ & 1.499 & 1.500 & $1.491 \pm 0.005$ & 1.482 & 1.482 \\
\hline $\mathrm{d}\left(\mathrm{N}-\mathrm{O}_{1}\right)(\AA)$ & 1.228 & 1.228 & $1.224 \pm 0.005$ & 1.195 & 1.196 \\
\hline $\mathrm{d}\left(\mathrm{N}_{-} \mathrm{O}_{2}\right)(\AA)$ & 1.228 & 1.228 & $1.224 \pm 0.005$ & 1.195 & 1.196 \\
\hline$\angle\left(\mathrm{H}_{1} \mathrm{CH}_{2,3}\right)($ deg. $)$ & 112.0 & 110.5 & - & - & - \\
\hline$\angle\left(\mathrm{H}_{2} \mathrm{CH}_{3}\right)($ deg. $)$ & 109.7 & 112.9 & - & - & - \\
\hline$\angle\left(\mathrm{H}_{1} \mathrm{CN}\right)($ deg. $)$ & 108.4 & 106.6 & $107.4 \pm 0.5$ & 107.7 & 106.5 \\
\hline$\angle\left(\mathrm{H}_{2,3} \mathrm{CN}\right)($ deg. $)$ & 107.2 & 108.0 & $107.4 \pm 0.5$ & 107.2 & 107.8 \\
\hline$\angle\left(\mathrm{CNO}_{1}\right)($ deg. $)$ & 117.8 & 117.2 & 117.4 & 117.8 & 117.2 \\
\hline$\angle\left(\mathrm{CNO}_{2}\right)($ deg. $)$ & 116.6 & 117.3 & 117.4 & 117.8 & 117.2 \\
\hline$\angle\left(\mathrm{O}_{1} \mathrm{NO}_{2}\right)($ deg. $)$ & 125.5 & 125.5 & $125.5 \pm 0.3$ & 125.6 & 125.6 \\
\hline$\angle\left(\mathrm{H}_{1} \mathrm{CNH}_{2,3}\right)($ deg. $)$ & 121.2 & 118.8 & - & - & - \\
\hline$\angle\left(\mathrm{H}_{2} \mathrm{CNH}_{3}\right)($ deg. $)$ & 117.7 & 122.4 & - & - & - \\
\hline Total energy (a.u. $)$ & $-244.9666^{\mathrm{b}}$ & $-244.9666^{\mathrm{b}}$ & - & -243.7239 & -243.7233 \\
\hline
\end{tabular}

The computed values reported in table 1 are in good agreement with the experimental microwave values of Cox and Waring [32]. The maximum numerical deviations from the experimental values are inferior to $0.01 \AA$ and $1.0^{\circ}$ for bond lengths and bond angles, respectively. The problems encountered in the prediction of the $\mathrm{N}-\mathrm{O}$ bond length in the RHF calculations of Allouche et al. [33], which were smaller than the experimental value by $0.03 \AA$, do not appear in the present calculations. Also, comparing the present values with the ones of reference [33], the consideration of correlation predicts the staggered and the eclipsed forms to be degenerate. The calculated energy difference is only 0.02 $\mathrm{kJ} \cdot \mathrm{mol}^{-1}$ in the limit of the computational approach used. Atomic charges were also computed using two different methods, i.e., from the traditional Mulliken definition and from a Natural Population Analysis, and are summarized in table 2. 
Table 2. Mulliken and NPA atomic charges in the nitromethane molecule.

\begin{tabular}{|c|c|c|c|c|}
\hline & \multicolumn{2}{|c|}{ Mulliken } & \multicolumn{2}{c|}{ NPA } \\
\hline atom & eclipsed & staggered & eclipsed & staggered \\
\hline $\mathrm{H}_{1}$ & 0.245 & 0.250 & 0.260 & 0.266 \\
\hline $\mathrm{H}_{2}, \mathrm{H}_{3}$ & 0.246 & 0.243 & 0.264 & 0.260 \\
\hline $\mathrm{C}$ & -0.512 & -0.511 & -0.523 & -0.523 \\
\hline $\mathrm{N}$ & 0.118 & 0.121 & 0.496 & 0.493 \\
\hline $\mathrm{O}_{1}$ & -0.181 & -0.173 & -0.376 & -0.379 \\
\hline $\mathrm{O}_{2}$ & -0.162 & -0.173 & -0.384 & -0.379 \\
\hline
\end{tabular}

The main difference between the two approaches is observed for the $\mathrm{NO}_{2}$ group where the Mulliken charges yield to weakly charged nitrogen and oxygen atoms. For the $\mathrm{CH}_{3}$ group both methods result in the same atomic charges. The differences in the atomic charges between the two conformers are negligible. Vibrational frequencies were also calculated for the two conformers and both are classified as true minima through explicit diagonalization of the hessian matrix. The computed values are in good agreement with the ultrafast IR-Raman spectroscopic data obtained by Deak and co-workers [34] considering liquid nitromethane and those are collected in table 3.

Table 3. Vibrational $\left(\mathrm{cm}^{-1}\right)$ calculated at the optimum geometries reported in table 1.

\begin{tabular}{|c|c|c|c|}
\hline Mode & eclipsed & staggered & exp. [34] \\
\hline$\tau\left(\mathrm{CH}_{3}\right)$ & 25 & 30 & $\sim 60$ \\
\hline$\delta(\mathrm{CNO})$ & 479 & 481 & 480 \\
\hline$\rho\left(\mathrm{NO}_{2}\right)$ & 615 & 607 & 607 \\
\hline$\delta(\mathrm{ONO})$ & 654 & 659 & 657 \\
\hline$v(\mathrm{CN})$ & 924 & 925 & 918 \\
\hline$\rho\left(\mathrm{CH}_{3}\right)$ & 1122,1144 & 1122,1145 & 1104,1125 \\
\hline$v\left(\mathrm{NO}_{2}\right)$ & 1417,1644 & 1417,1644 & 1379,1560 \\
\hline$\delta\left(\mathrm{CH}_{3}\right)$ & $1444,1484,1496$ & $1444,1484,1496$ & $1402,1426,1426$ \\
\hline$v\left(\mathrm{CH}_{3}\right)$ & $3101,3190,3223$ & $3099,3192,3224$ & $2968,3050,3050$ \\
\hline
\end{tabular}

The structure of nitromethane is analogous to the structure of the adsorbed formate anion ( $\mathrm{HCOO}^{-}$) which is known, from theoretical [18] and experimental work [35], to adsorb on single metal surfaces by its oxygen atoms. Thus, following the previous theoretical work on the adsorption of formate on low index copper surfaces [18] and based also on experimental information [16], two different starting geometries were idealized, see Figure 3. 

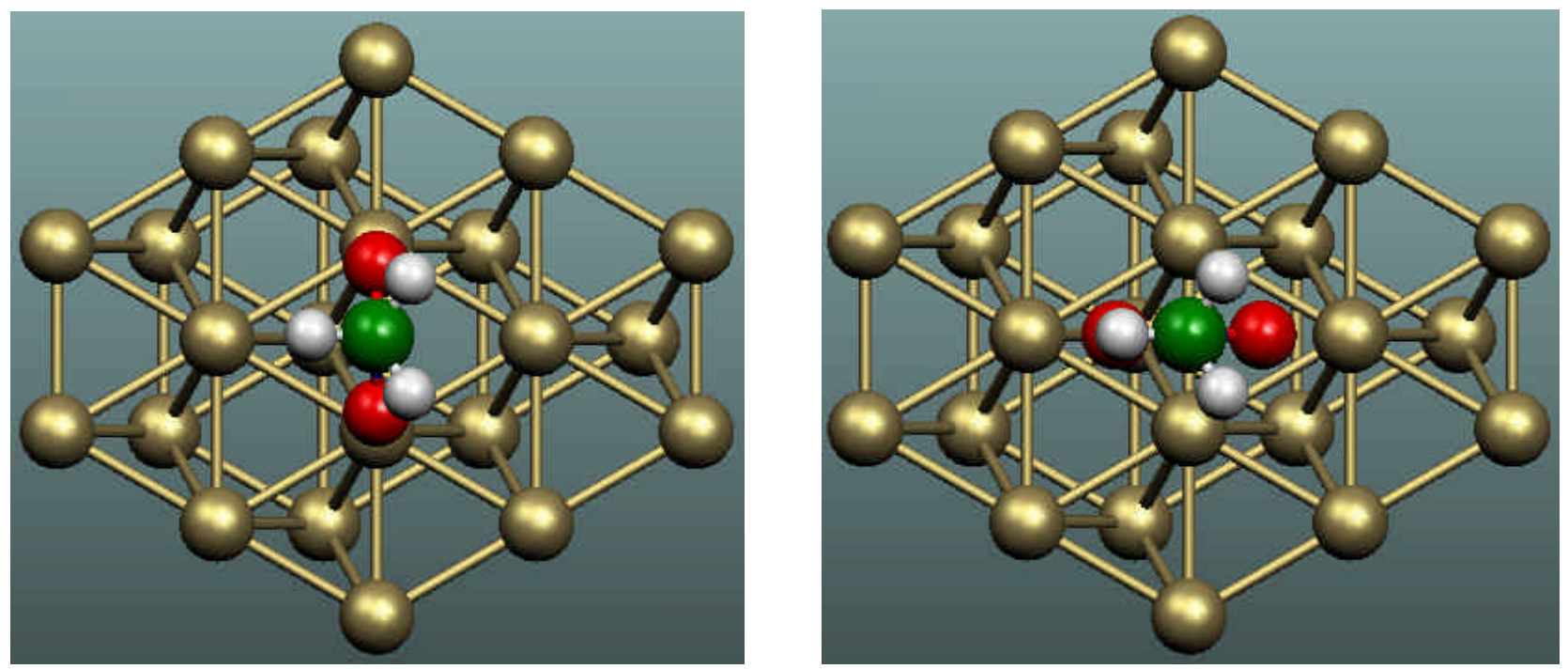

Figure 3. Starting geometries for the nitromethane molecule. Both structures are bidentate, adsorbed on a short-bridge site, left, or on a long-bridge site, right, of the $\mathrm{Au}(111)$ surface.

In a first part of our calculations, the plane of the molecule was kept perpendicular to the metal surface, following the previous results for formate. Then, a partial optimization of the internal geometry of nitromethane was taken into account with a symmetric displacement of the oxygen atoms in the coordinate that defines each of the bridge sites. This prevents the jump of the nitromethane molecule to a different and not interesting conformation. The results obtained for the two-adsorption geometries are summarized in Table 4. In these two optimized geometries, the nitrogen atom is located practically above the intersection of the two bridge sites and the final optimized $\mathrm{CH}_{3} \mathrm{NO}_{2}$ structures are identical. The two oxygen atoms are located at the same perpendicular distance to the gold surface. An important point is that for the long-bridge site, the two oxygen atoms are practically at the same distance from the surface despite the fact that these two are placed above two different hollow sites, hcp and fcc. This is a contradictory behavior when compared with the adsorption of formate on the long-bridge sites of the copper surfaces [18]. Formate adsorbs on the long-bridge sites of copper with the two oxygen atoms placed at significantly different distances from the metal surface and this is accompanied by a tilt of the molecule. Probably, this is due to the fact that the gold atoms are larger than copper atoms and the two cavities in the gold surface have comparable sizes. The distance from the nitromethane oxygen atoms to the metal surface is larger than the observed for formate on copper. However, this is not a sign of a different behavior of the nitromethane bonding since it is known that adsorption on gold surfaces is much weaker than on copper [36]. For example, methoxy adsorption energy on the most stable sites of copper and gold is of about $241 \mathrm{~kJ} / \mathrm{mol}$ and $85 \mathrm{~kJ} / \mathrm{mol}$ respectively [36]. Furthermore, the adsorbate to surface distance increases from copper to gold by $\sim 0.3 \AA$.

For the two bridge-sites, the calculated adsorption energy of nitromethane on $\mathrm{Au}(111)$ is small, $\sim 20$ $\mathrm{kJ} / \mathrm{mol}$. The most stable site is the long-bridge with an energy of $22.4 \mathrm{~kJ} / \mathrm{mol}$ while on the short-bridge site the interaction energy is $18.9 \mathrm{~kJ} / \mathrm{mol}$. This low adsorption energy is a sign of a small interaction with the surface as seen also from the large adsorbate to surface distance. The internal geometry of the adsorbate is practically the same of the gas-phase nitromethane molecule, c.f. Table 1, as expected from the small interaction energy. The more important difference is that the $\mathrm{N}-\mathrm{O}$ bonds are elongated by $\sim 0.02 \AA$ which is a sign that, despite the low interaction energy, there is some activation of the $\mathrm{N}-\mathrm{O}$ bonds. 
Table 4. Calculated geometrical parameters for nitromethane adsorbed on the $\mathrm{Au}(111)$ surface.

\begin{tabular}{|c|c|c|c|}
\hline & short-bridge & long-bridge & full-optimization \\
\hline $\mathrm{d}\left(\mathrm{nnAu}-\mathrm{O}_{1}\right)(\AA)$ & 3.298 & 3.757 & 3.497 \\
\hline $\mathrm{d}\left(\mathrm{nnAu}-\mathrm{O}_{2}\right)(\AA)$ & 3.298 & 3.768 & 5.436 \\
\hline $\mathrm{d}\left(\right.$ surf.- $\left.\mathrm{O}_{1}\right)(\AA)$ & 3.283 & 3.493 & 3.249 \\
\hline$d\left(\right.$ surf.- $\left.\mathrm{O}_{2}\right)(\AA)$ & 3.283 & 3.504 & 5.381 \\
\hline $\mathrm{d}\left(\mathrm{C}-\mathrm{H}_{1}\right)(\AA)$ & 1.090 & 1.090 & 1.087 \\
\hline $\mathrm{d}\left(\mathrm{C}-\mathrm{H}_{2,3}\right)(\AA)$ & 1.090 & 1.090 & 1.091 \\
\hline $\mathrm{d}(\mathrm{C}-\mathrm{N})(\AA)$ & 1.497 & 1.499 & 1.499 \\
\hline $\mathrm{d}\left(\mathrm{N}-\mathrm{O}_{1}\right)(\AA)$ & 1.250 & 1.240 & 1.262 \\
\hline $\mathrm{d}\left(\mathrm{N}-\mathrm{O}_{2}\right)(\AA)$ & 1.250 & 1.239 & 1.262 \\
\hline $\mathrm{d}\left(\mathrm{O}_{1}-\mathrm{O}_{2}\right)(\AA)$ & 2.258 & 2.224 & 2.235 \\
\hline$\angle\left(\mathrm{H}_{1} \mathrm{CN}\right)($ deg. $)$ & 108.0 & 107.7 & 107.8 \\
\hline$\angle\left(\mathrm{H}_{2,3} \mathrm{CN}\right)($ deg. $)$ & 108.0 & 107.7 & 107.6 \\
\hline$\angle\left(\mathrm{CNO}_{1}\right)($ deg. $)$ & 115.4 & 115.6 & 117.3 \\
\hline$\angle\left(\mathrm{CNO}_{2}\right)($ deg. $)$ & 115.4 & 116.8 & 118.3 \\
\hline$\angle\left(\mathrm{O}_{1} \mathrm{NO}_{2}\right)($ deg. $)$ & 129.3 & 127.5 & 124.5 \\
\hline$\angle$ (NM plane -surf.) (deg.) & 0.0 & 0.0 & 13.4 \\
\hline $\mathrm{E}_{\mathrm{ads}}(\mathrm{kJ} / \mathrm{mol})$ & 18.9 & 22.4 & 24.0 \\
\hline $\mathrm{q}_{\text {adsorbate }}$ Mulliken (a.u.) & 0.17 & 0.09 & 0.15 \\
\hline
\end{tabular}

The partial optimized structure obtained for the long-bridge was used as a starting point for a subsequent calculation where the adsorbed nitromethane molecule was free to move on the surface while its internal geometry was optimized. The geometric parameters for this structure are also reported in Table 4 and part of them reproduced in Figure 4.
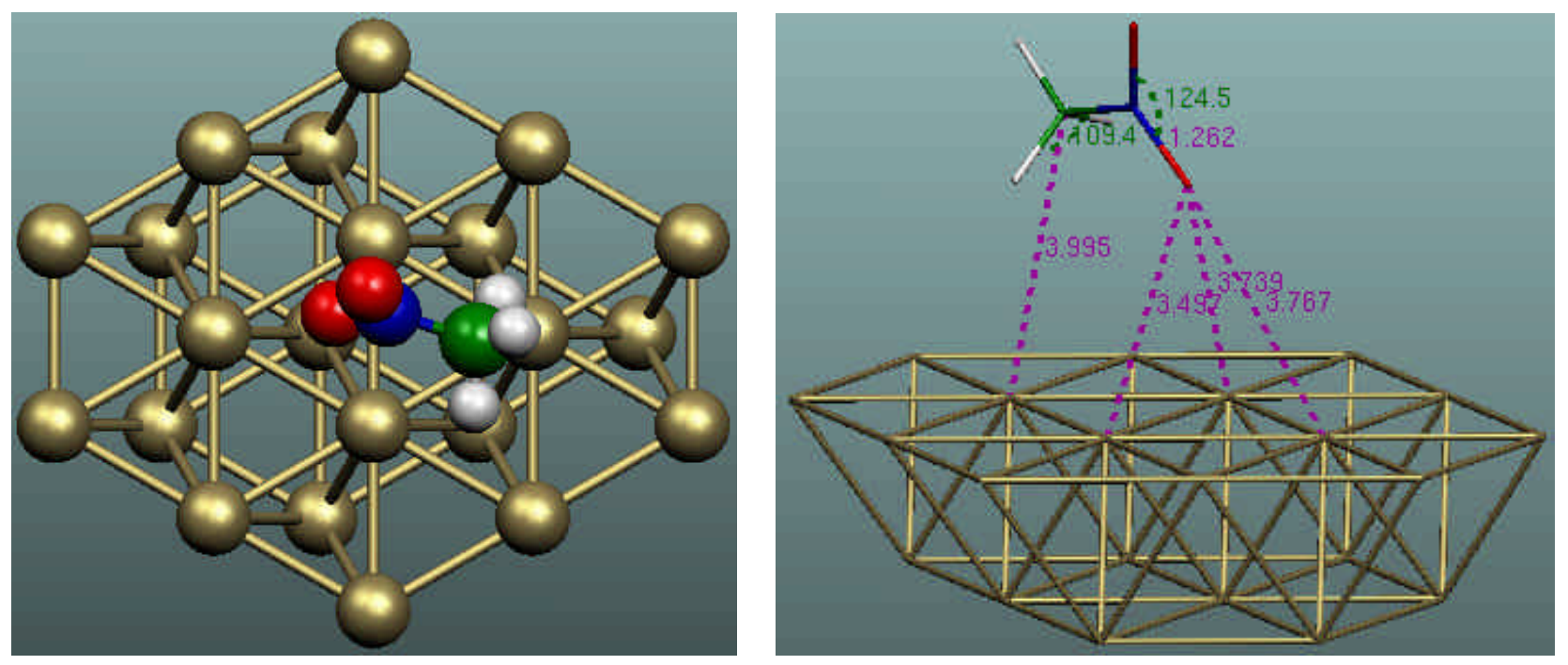

Figure 4. Top and side views of the final optimized geometry for the nitromethane molecule adsorbed on the $\mathrm{Au}(111)$ surface. 
The structure found in the present calculations is in good agreement with the predictions from the experimental work of Wang et al. [16]. The high-resolution electron energy loss spectroscopy (HREELS) results ruled out bidentate adsorption forms of the nitromethane molecule on the $\mathrm{Au}(111)$ surface. Furthermore, these authors suggest that a monodentate species with the $\mathrm{C}-\mathrm{N}$ bond axis nearly parallel to the surface is the most likely structure on the surface and added that due to the weak interaction with the metal surface, possibly, the molecular plane is normal to the surface. The present calculations add further support to this assignment, the monodentate-bonding scheme is found to be energetically preferred. In the fully optimized geometry the molecular plane of adsorbed nitromethane is tilted from the surface normal by only $\sim 13^{\circ}$ and, as can be easily seen from figure 4 , the C-N bond is almost parallel to the surface. The internal geometry of adsorbed nitromethane is close to that for the molecule in the gas-phase. However, it is worth pointing out that the energy difference between the fulloptimized structure and those coming from the adsorption on the long-bridge site is really small. The difference between the adsorption energy of the conformation illustrated in Figure 4 and that calculated for the nitromethane molecule adsorbed with the oxygen atom of the $\mathrm{NO}_{2}$ group in the fcc hollow site (only the second metal layer is changed) is negligible. A similar conclusion was taken in a previous work for propyne adsorption on $\mathrm{Cu}(111)$ [37]. The full-optimized structure closely resembles those from the adsorbed methyl nitrite [24] and we may conclude for monolayer coverage, the ratio of one nitromethane molecule per three surface atoms.

\section{Conclusions}

The density functional calculations reported in this work, for the adsorption of the nitromethane molecule on gold (111) surface predicts a weak interaction of this molecule with the surface. This is consistent with the fact that the computed geometry for the adsorbed molecule closely resembles that of the gas-phase molecule. In addition, the calculated, full-optimized, geometry for adsorbed nitromethane is in an excellent agreement with the proposed experimental geometry. The C-N bond is parallel to the surface while the molecular plane is softly tilted from the normal to the gold surface.

\section{Acknowledgements}

This research has been supported by the Spanish DGICYT grant PB98-1216-C02-01 and, in part, by Generalitat de Catalunya grant 1999SGR-00040. J.R.B.G. thanks the Fundação para a Ciência e a Tecnologia for a post-doc grant (BPD/22098/99). Part of the computer time was provided by the Cen-

tre de Supercomputació de Catalunya, CESCA, and Centre Europeu de Paral.lelisme de Barcelona, CEPBA, through a grant from the Fundació Catalana de la Recerca.

\section{References and Notes}

1. Laine, R. M. Catal. Rev. Sci. Eng. 1983, 25, 459.

2. Gates, B. C.; Katzer, J. R.; Schuit, G. C. A. Chemistry of Catalytic Processes, McGraw-Hill: New York, 1979.

3. Sutton, G. P. Rocket Propulsion Elements, Wiley, New York, 1963. 
4. Cromer, D. T.; Ryan, R. R.; Schiferl, D., J. Phys. Chem. 1985, 89, 3215.

5. Wodtke, A. M.; Hintsa, E. J.; Lee, Y. T. J. Chem. Phys. 1986, 84, 1044.

6. $\quad$ Engelke, R.; Earl, W. L.; Rohlfing, C. M. J. Chem. Phys. 1986, 84, 142.

7. Pressley, L. A.; Pylant, E. D.; White, J. M. Surf. Sci. 1996, 367, 1.

8. Russel Jr., J. N.; Gates, S. M.; Yates Jr., J. T. Surf. Sci. 1985, 163, 516.

9. Bowker, M.; Madix, R. J. Surf. Sci. 1980, 95, 190.

10. Gomes, J. R. B.; Gomes, J. A. N. F.; Illas, F. Surf. Sci. 1999, 443, 165.

11. Gomes, J. R. B.; Gomes, J. A. N. F. Surf. Sci. 2001, 471, 59.

12. Benziger, J. B. Appl. Surf. Sci. 1984, 17, 309.

13. Hwang, S. Y.; Kong, A. C. F.; Schmidt, L. D. J. Phys. Chem. 1989, 93, 8334.

14. Hwang, S. Y.; Kong, A. C. F.; Schmidt, L. D. Surf. Sci. 1989, 217, 179.

15. Saliba, N.; Wang, J.; Bansenauer, B. A.; Koel, B. E. Surf. Sci. 1997, 389, 147.

16. Wang, J.; Bansenauer, B. A.; Koel, B. E. Langmuir 1998, 14, 3255.

17. Peck, J. W.; Mahon, D. I.; Beck, D. E.; Koel, B. E. Surf. Sci. 1998, 410, 170.

18. Gomes, J. R. B.; Gomes, J. A. N. F. Surf. Sci. 1999, 432, 279.

19. Ricca, A.; Bauschlicher, C.W. J. Phys. Chem. 1994, 98, 12899.

20. Russo, T.V.; Martin, R.L.; Hay, P.J. J. Chem. Phys. 1995, 102, 8023.

21. Ricca, A.; Bauschlicher, C.W. Theor. Chim. Acta 1995, 92, 123.

22. Baerends, E.J.; Grisenko, O.V. J. Phys. Chem. A 1997, 101, 5383.

23. Siegbahn, P.E.M.; Crabtree, R.H. J. Am. Chem. Soc. 1997, 119, 3103.

24. Gomes, J. R. B.; Illas, F. Catal. Lett. 2001, 71, 31.

25. Illas, F.; Sousa, C.; Gomes, J. R. B.; Clotet, A.; Ricart, J. M. in Theoretical Aspects of Heterogeneous Catalysis, Nascimento, M., Ed.; Kluwer, 2001.

26. Becke, A. D. Phys. Rev. A 1998, 38, 3098.

27. Lee, C.; Yang, W.; Parr, R. G. Phys. Rev. B 1980, 37, 785.

28. Colle, R.; Salvetti, O. Theor. Chim. Acta 1975, 37, 329.

29. Colle, R.; Salvetti, O. Theor. Chim. Acta 1979, 53, 55.

30. Hay, P. J.; Wadt, W. R. J. Chem. Phys. 1985, 82, 270.

31. Frisch, M.J.; Trucks, G.W.; Schlegel, H.B.; Scuseria, G.E.; Robb, M.A.; Cheeseman, J.R.; Zakrzewski, V.G.; Montgomery, J.A., Jr.; Stratmann, R.E.; Burant, J.C.; Dapprich, S.; Millam, J.M.; Daniels, A.D.; Kudin, K.N.; Strain, M.C.; Farkas, O.; Tomasi, J.; Barone, V.; Cossi, M.; Cammi, R.; Mennucci, B.; Pomelli, C.; Adamo, C.; Clifford, S.; Ochterski, J.; Petersson, G.A.; Ayala, P.Y.; Cui, Q.; Morokuma, K.; Malick, D.K.; Rabuck, A.D.; Raghavachari, K.; Foresman, J.B.; Cioslowski, J.; Ortiz, J.V.; Baboul, A.G.; Stefanov, B.B.; Liu, G.; Liashenko, A.; Piskorz, P.; Komaromi, I.; Gomperts, R.; Martin, R.L.; Fox, D.J.; Keith, T.; Al-Laham, M.A.; Peng, C.Y.; Nanayakkara, A.; Gonzalez, C.; Challacombe, M.; Gill, P.M.W.; Johnson, B.; Chen, W.; Wong, 
M.W.; Andres, J.L.; Gonzalez, C.; Head-Gordon, M.; Replogle, E.S.; Pople, J.A. Gaussian 98, Revision A.7; Gaussian: Pittsburgh PA, 1998.

32. Cox, A. P.; Waring, S. J. Chem. Soc. Farad. Trans. II 1972, 68, 1060.

33. Allouche, A. J. Phys. Chem. 1996, 100, 1820.

34. Deak, J.C.; Iwaki, L. K.; Dlott, D. D. J. Phys. Chem. A 1999, 103, 971.

35. Woodruff, D. P.; McConville, C. F.; Kilcoyne, A. L. D.; Lindner, Th.; Somers, J.; Surman, M.; Paolucci, G.; Bradshaw, A. M. Surf. Sci., 1988, 201, 228.

36. Gomes, J. R. B.; Gomes, J. A. N. F. J. Mol. Struct. (Theochem), 2000, 503, 189.

37. Valcarcel, A.; Ricart, J. M.; Clotet, A.; Markovits, A.; Minot, C.; Illas, F. J. Chem. Phys., in press.

(C) 2001 by MDPI (http://www.mdpi.org). 